\title{
Electrochemical Synthesis of Gold and Protein Gradients on Particle Surfaces
}

\author{
Kristofer Eriksson, ${ }^{\dagger}$ Pål Palmgren, ${ }^{\ddagger}$ Leif Nyholm, ${ }^{*}, \S$ and Sven Oscarsson ${ }^{\dagger}$ \\ ${ }^{\dagger}$ Department of Organic Chemistry, Stockholm University, Arrhenius Laboratory, SE-106 91 Stockholm, Sweden \\ ${ }^{\ddagger}$ Department of Physics and Astronomy, Uppsala University, Box 516, S-751 20 Uppsala, Sweden \\ ${ }^{\S}$ Department of Chemistry, The Ångström Laboratory, Uppsala University, Box 538, SE-75121, Uppsala, Sweden
}

\section{Supporting Information}

ABSTRACT: A straightforward, versatile approach to the production of protein gradients on planar and spherical particle surfaces is described. The method is based on the spatially controlled oxidation of thiolated surfaces by $\mathrm{Au}(\mathrm{III})$ ions generated via the electrochemical oxidation of a gold electrode in a phosphate-buffered saline solution (10 mM PBS, $\mathrm{pH} 7.2,150 \mathrm{mM}$ $\mathrm{NaCl}$ ). Because the gold electrode is in direct contact with the thiolated

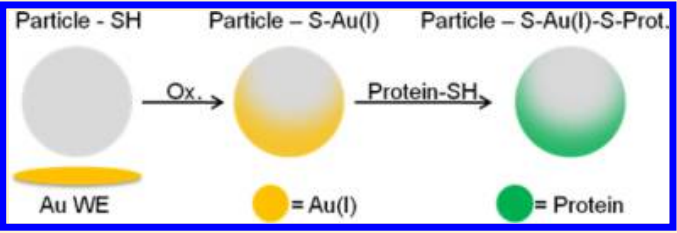
surfaces, the released $\mathrm{Au}(\mathrm{III})$ ions, which are present as $\mathrm{Au}(\mathrm{III})$ chloride complexes, give rise to the formation of a surface gradient of $\mathrm{Au}(\mathrm{I})$-thiolate complexes depending on the local redox potential given by the local $\mathrm{Au}(\mathrm{III})$ concentration. As is shown on the basis of the use of X-ray photoelectron spectroscopy and fluorescently labeled proteins, the $\mathrm{Au}(\mathrm{I})$-thiolate complexes can subsequently be functionalized with thiolated proteins, yielding surface density protein gradients on micrometer-sized nonconducting polymer beads as well as linear Au(I)-thiolate gradients on planar silicon surfaces.

\section{INTRODUCTION}

Several fundamental biological processes depend on gradients of biomolecules, such as proteins, on surfaces. Surface-confined proteins stimulate human cells to migrate, proliferate, or differentiate, ${ }^{1-5}$ which are fundamental phenomena required for wound healing, the immune response, and tumor metastasis. Surface density gradients are also versatile tools in various biosensor $^{6-8}$ and catalysis ${ }^{9,10}$ applications. At present, there are several techniques that can be used to produce molecular gradients on surfaces. Approaches such as microfluidics, ${ }^{11-14}$ plasma polymerization, ${ }^{15-17}$ and diffusion procedures through liquid droplets, ${ }^{18}$ hydrogel networks, ${ }^{19}$ and agarose ${ }^{20}$ or dextran $^{21,22}$ gels have thus been described. Photoactive molecules have likewise been used on the basis of photoimmobilization techniques, in which the light intensity and exposure times ${ }^{23-26}$ are controlled, or by employing photolithography. ${ }^{27,28}$ More automated and computerized methods such as inkjet printing ${ }^{29}$ and "control dipping" ${ }^{\text {"30 }}$ have also been described. Gradients have also been generated with various techniques based on surface-confined electrochemistry, using in-plane electrochemical potentials for the reductive desorption of thiol layers, ${ }^{31-33}$ corona discharge, ${ }^{34}$ scanning electrochemical microscopy, ${ }^{9,35}$ and bipolar electrodes. ${ }^{36,37}$ However, the manufacturing of density gradients has so far been limited to planar surfaces.

We have recently shown ${ }^{38}$ that electrochemical reactions can be used to manufacture anisotropic particles based on the sitespecific oxidation of thiols present on the surfaces of polymeric particles. This method involves the oxidation of the segment of the particle in contact with a glassy carbon or gold electrode. In this letter, we show that this approach also enables the straightforward, versatile production of surface density molecular gradients on the surfaces of nonconducting polymer particles, provided that a gold electrode is used. To the best of our knowledge, this is the first report regarding such a method that also can be used for the straightforward generation of gradients on planar thiolated surfaces.

\section{EXPERIMENTAL SECTION}

Thiol Functionalization of Surfaces. The reactions employed to introduce thiols onto the surfaces of polymer particles and silicon wafers as well as onto proteins have been described elsewhere. ${ }^{38} \mathrm{~A}$ brief description of these reactions can also be found in the Supporting Information.

Potentiostatic Experiments. The thiolated surfaces (i.e., the particles that had an average diameter of $4.9 \mu \mathrm{m}$ with a standard deviation of $0.2 \mu \mathrm{m}$ (Micromod Partikeltechnologie $\mathrm{GmbH}$ )) or the silicon wafer was put in a Teflon beaker with an inner diameter of 0.9 $\mathrm{cm}$ containing $4 \mathrm{~mL}$ of PBS and was used in an electrochemical threeelectrode setup comprising a gold working electrode, a gold counter electrode, and a platinum quasi-reference electrode. Typically, $2 \mathrm{~mL}$ of particles (i.e., $8.75 \times 10^{6}$ particles $/ \mathrm{mL}$ ), with approximately $1 \times 10^{8}$ thiol groups per particle, was added to the beaker and allowed to distribute on the gold surface for $10 \mathrm{~min}$. The silicon surface was tilted against the gold working electrode and the inner wall of the Teflon beaker at an angle of approximately $26^{\circ}$. A potential of $+0.9 \mathrm{~V}(\mathrm{vs} \mathrm{Pt})$ was then applied to the gold working electrode.

X-ray Photoelectron Spectroscopy. The formation of $\mathrm{Au}(\mathrm{I})$ thiolates on the surfaces of the particles and silicon wafers was investigated with X-ray photoelectron spectroscopy (XPS) employing

Received: April 30, 2012

Revised: June 18, 2012

Published: July 2, 2012 
a Scienta ESCA-300 spectrometer using monochromatic $\mathrm{Al} \mathrm{K \alpha}$ radiation with a photon energy of $1487 \mathrm{eV}$. The particles were dried onto a piece of $1 \times 1 \mathrm{~cm}^{2}$ conductive glass prior to the XPS measurements. The recorded spectra for the silicon wafers were referenced to the Si $2 \mathrm{p}$ core level at a binding energy of $99.3 \mathrm{eV}$. For the particles, the reference was instead made to the Sn $3 \mathrm{~d}$ core level at $486.6 \mathrm{eV}(\mathrm{Sn}(\mathrm{IV})){ }^{44}$ The binding-energy scale was the Fermi level adjusted by measuring the Au $4 \mathrm{f}$ level of a clean Au foil. The spectra were recorded at normal photoelectron emission.

\section{RESULTS AND DISCUSSION}

Thiol-functionalized magnetic polymer particles with a diameter of $4.9 \mu \mathrm{m}$, which were suspended in a physiological buffer containing sodium chloride (10 mM PBS, $\mathrm{pH} 7.2,150$ $\mathrm{mM} \mathrm{NaCl}$ ), were attracted to a gold working electrode surface by an external magnet mounted underneath the electrode as is depicted in Figure 1. A potential of $+0.9 \mathrm{~V}$ versus a Pt quasi-

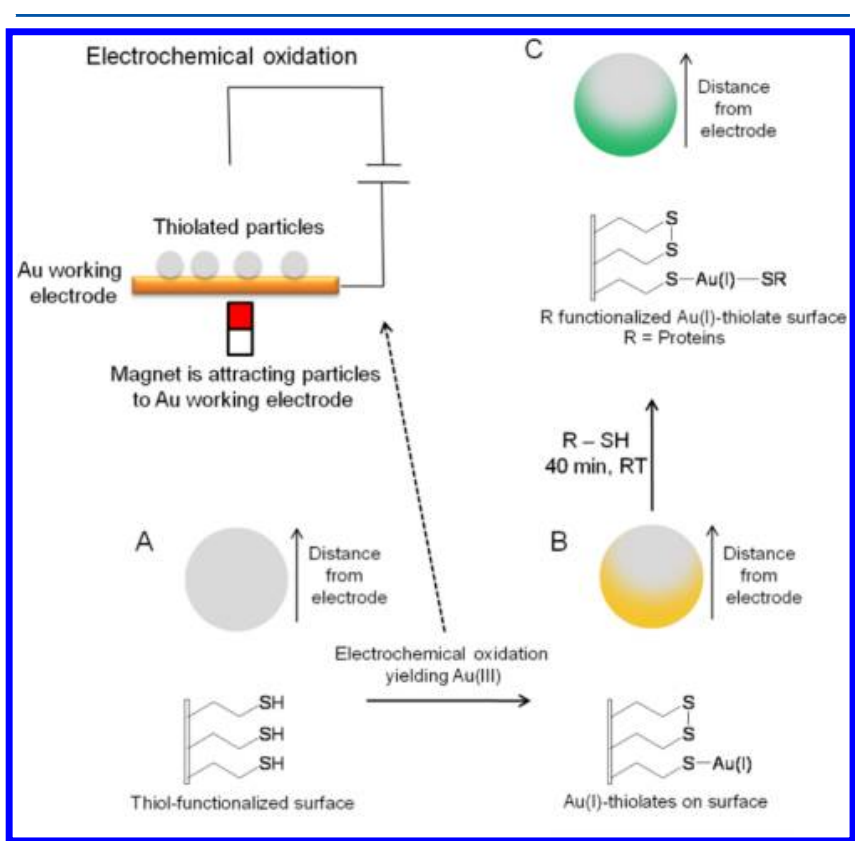

Figure 1. Fabrication of protein gradients on the surfaces of nonconducting polymer particles. (A) Thiol-functionalized particles are oxidized by released $\mathrm{Au}$ (III) chloride complexes to yield (B) a gradient of $\mathrm{Au}(\mathrm{I})$-thiolate complexes on its surface. (C) Proteins are conjugated to the $\mathrm{Au}(\mathrm{I})$ thiolates to generate a surface density protein gradient.

reference electrode was then applied to the gold electrode to generate $\mathrm{Au}$ (III) ions in the vicinity of the gold surface. These $\mathrm{Au}(\mathrm{III})$ ions, which are present as $\mathrm{Au}(\mathrm{III})$ chloride complexes, diffuse into the electrolyte solution and react with the thiolated surfaces to yield disulfides and surface-confined $\mathrm{Au}(\mathrm{I})$-thiolate complexes (Figure 1). Although this formation of $\mathrm{Au}(\mathrm{I})$ thiolates as a result of the oxidation of the thiols by $\mathrm{Au}$ (III) ions is well known and has been utilized for the generation of thiolsupported gold nanoparticles, ${ }^{39}$ we are not aware of any previous reports of its use in the oxidative generation of surface density gradients.

More explicitly, the $\mathrm{Au}(\mathrm{I})$-thiolate gradients are formed as a result of the fact that the particles are spherical because this causes the surface-bound thiols to be located different distances from the electrode surface (i.e., at different positions in the $\mathrm{Au}(\mathrm{III})$ diffusion layer). Thiols close to the gold working electrode will thus be exposed to a higher $\mathrm{Au}(\mathrm{III})$ concentration (i.e., a more positive redox potential) than thiols anchored on top of the particles as is depicted in Figure $1 \mathrm{~b}$. Finally, thiol-functionalized immunoglobulin G (IgG) was conjugated to the surface-bound gold atoms via gold-sulfur bonds (Figure 1c) to generate protein surface density gradients.

The present approach consequently relies on the generation of $\mathrm{Au}$ (III) chloride complexes acting as oxidation agents with respect to the surface-immobilized thiol groups. Figure 2 shows

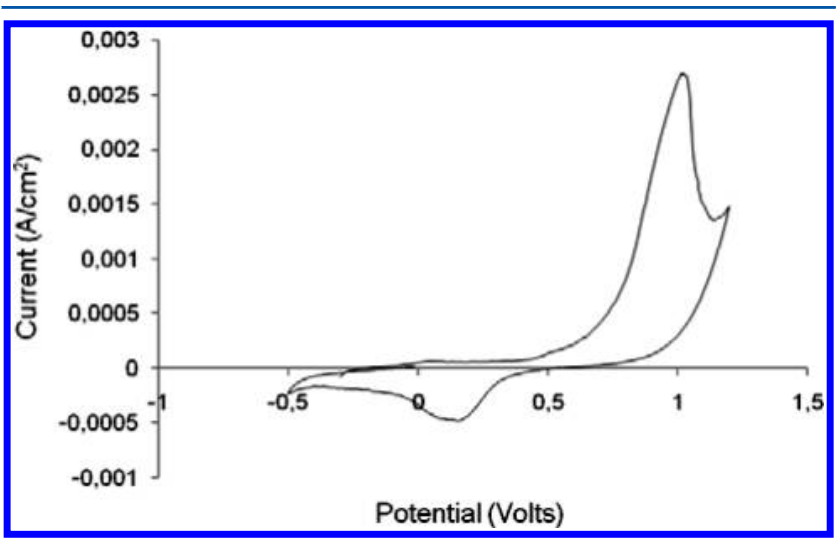

Figure 2. Cyclic voltammogram recorded for a gold electrode in PBS buffer containing $0.15 \mathrm{M}$ chloride employing a scan rate of $50 \mathrm{mV} / \mathrm{s}$.

a cyclic voltammogram recorded for the gold electrode in 10 $\mathrm{mM}$ sodium phosphate buffer ( $\mathrm{pH} 7.2$ ) containing $0.15 \mathrm{M}$ sodium chloride and employing a three-electrode setup with a gold counter electrode and a platinum quasi-reference electrode. (The potential of this electrode was $+0.31 \mathrm{~V}$ vs a $\mathrm{Ag} / \mathrm{AgCl}$ reference electrode.) It is seen that the oxidation of the gold electrode commenced at about $+0.7 \mathrm{~V}$ and that the oxidation charge was significantly larger than the reduction charge, indicating the formation of soluble $\mathrm{Au}(\mathrm{III})$ chloride complexes. The release of $\mathrm{Au}(\mathrm{III})$ ions from gold electrodes in the presence of a complexing agent such as chloride is not surprising because this phenomenon has been described previously. ${ }^{40,41}$ More importantly, the release of the $\mathrm{Au}(\mathrm{III})$ species gives rise to an $\mathrm{Au}(\mathrm{III})$ concentration gradient in the vicinity of the gold electrode. Because the $\mathrm{Au}$ (III) chloride species are good oxidizing agents, the local redox potential will thus depend on the oxidation time as well as the distance between the particles and the gold electrode, indicating that the thiols on the surfaces of particles will experience different redox potentials depending on the positions of the thiols with respect to the electrode surface. This redox potential gradient (which will also depend on the particle number density) is responsible for the generation of the gradients of disulfides and $\mathrm{Au}(\mathrm{I})$ thiolates on the surfaces of the particles. For a preset oxidation time, the obtained surface gradients will also naturally depend on the size of particles used in the experiment.

After the partial oxidation of the particles, the thiolated particles were investigated with X-ray photoelectron spectroscopy (XPS). The formation of $\mathrm{Au}(\mathrm{I})$-thiolates was confirmed by detecting the presence of $\mathrm{Au}(\mathrm{I})$ species on the surfaces of the particles (Supporting Information, Figure S1). No $\mathrm{Au}(\mathrm{I})$ could be detected on the particles in the absence of the oxidation step.

As depicted in Figure 3, the $\mathrm{Au}(\mathrm{I})$-thiolate gradients could be used to generate gradients of proteins on the surfaces of the particles. To enable fluorescence microscope studies of the protein gradients, fluorescein isothiocyanate (FITC)-labeled 


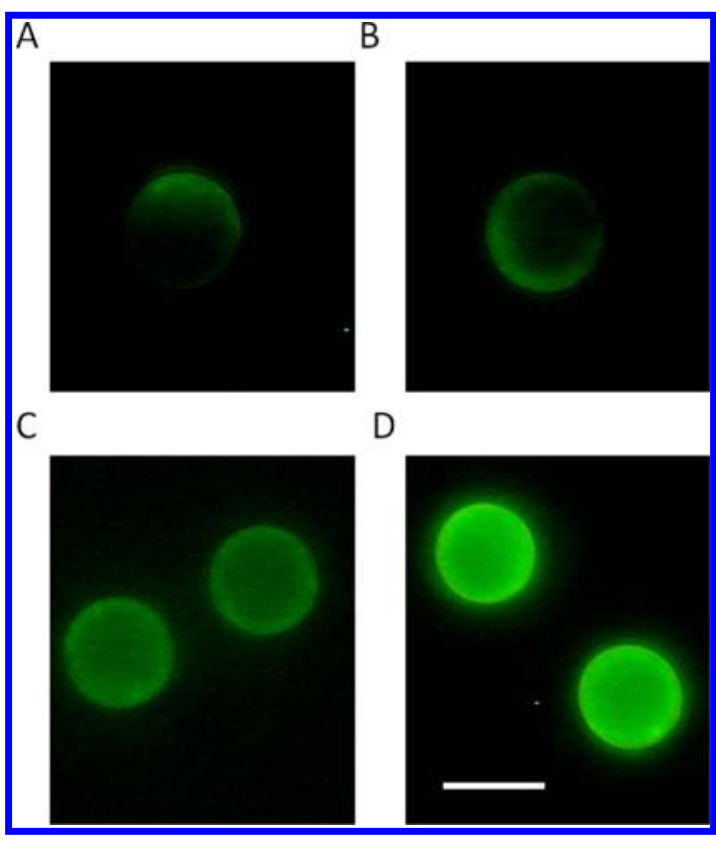

Figure 3. Fluorescence microscopy images of particles with protein molecular gradients obtained after oxidation at $+0.9 \mathrm{~V}$ (vs Pt) for (A, B) $0.1,(C) 1$, and (D) $10 \mathrm{~s}$. Note the protein gradients on the particles in $\mathrm{A}$ and $\mathrm{B}$ and the different fluorescence intensities in $\mathrm{C}$ and $\mathrm{D}$. The length of the scale bar corresponds to $5 \mu \mathrm{m}$.

IgG molecules were employed. The particles were first oxidized at $+0.9 \mathrm{~V}$ (vs $\mathrm{Pt}$ ) using different oxidation times and thereafter treated with thiolated proteins. For the shortest oxidation times (i.e., $0.1 \mathrm{~s}$ ), fluorescence intensity gradients were clearly seen on the individual particles, as is seen in Figure 3a,b. For longer oxidation times (i.e., 1 and 10 s, respectively; see Figure 3c,d), entire particles were instead found to emit fluorescence radiation of approximately the same intensity. When comparing particles oxidized for 1 and $10 \mathrm{~s}$, respectively, it is immediately evident that the fluorescence intensity was significantly higher for the longer oxidation time. The latter can be explained by the fact that the longer oxidation time results in a higher $\mathrm{Au}$ (III) concentration in the vicinity of the particles, which should give rise to a higher degree of oxidation and thus a higher concentration of protein on the surfaces of the particles. No fluorescence intensity was seen for particles that had not undergone the oxidative treatment. The latter indicates that there was no significant immobilization of the thiolated protein as a result of disulfide formation with the thiols immobilized on the particles. It is therefore clear that the immobilization of the thiolated proteins relies on the presence of the $\mathrm{Au}(\mathrm{I})$-thiolates generated in the oxidation of the thiols by the released $\mathrm{Au}$ (III) ions.

The present results also indicate that sufficiently short oxidation times are needed to obtain $\mathrm{Au}(\mathrm{I})$-thiolate gradients on individual particles whereas longer oxidation times result in an oxidation of the entire surfaces of the particles as a result of the growth of the $\mathrm{Au}(\mathrm{III})$ diffusion layer with time. The experimental results are in fact in good agreement with estimations of the diffusion layer thickness based on the following equation: $\Delta=(2 D t)^{1 / 2}$ in which $\Delta, D$, and $t$ denote the distance, the diffusion coefficient, and the time, respectively. ${ }^{42}$ For an oxidation time of $0.1 \mathrm{~s}$, the thickness of the diffusion layer can then be estimated to be about $4.5 \mu \mathrm{m}$, assuming a diffusion coefficient of $10^{-6} \mathrm{~cm}^{2} / \mathrm{s}$. Because this value is of the same order of magnitude as the diameter of the particles, it is reasonable to expect the formation of partially oxidized surfaces under these experimental conditions. For oxidation times of 1 and $10 \mathrm{~s}$, the corresponding values are 14 and $45 \mu \mathrm{m}$, respectively, indicating that these oxidation times should indeed give rise to homogeneous oxidation of the entire surfaces of the particles. These straightforward calculations hence demonstrate the possibility of producing batchwise surface density gradients on nonconducting polymer particles merely by controlling the length of the $\mathrm{Au}$ oxidation pulse. These findings are also in excellent agreement with our previous finding ${ }^{38}$ that dots, rather than gradients of surfaceconfined $\mathrm{Au}(\mathrm{I})$ species, were obtained on single particles when an oxidation time of $0.1 \mathrm{~s}$ was used with a gold electrode. The present approach can hence be used to generate both surface gradients (of $\mathrm{Au}(\mathrm{I})$-thiolate or proteins) on individual particles (i.e., patchy particles) and homogeneously coated particles with different surface concentrations of $\mathrm{Au}(\mathrm{I})$-thiolate or proteins. In the latter case, the surface concentrations of $\mathrm{Au}(\mathrm{I})$-thiolate or protein will depend on where in the $\mathrm{Au}(\mathrm{III})$ concentration gradient the particles were located during the oxidation step.

To model the gold gradient on the particles and to estimate how the concentration of gold adsorbed along the gradient varies with distance from the electrode, experiments were also carried out with planar thiol-functionalized silicon surfaces. In this case, gradients could be generated when the silicon surface was tilted against the gold working electrode because this induced a varying distance between the gold electrode and the different positions on the silicon surface hosting the thiol groups (the tilt angle was approximately $26^{\circ}$ ). In these experiments, an oxidation potential of $+0.9 \mathrm{~V}$ (vs $\mathrm{Pt}$ ) was employed for $60 \mathrm{~s}$ and the $\mathrm{Au}(\mathrm{I})$-thiolate density along the silicon surface was determined by probing the $\mathrm{Au}(\mathrm{I})$ intensity as a function of the position employing XPS (Figure 4a). The XPS measurements were performed at four different positions corresponding to distances of approximately (i) 0.5 , (ii) 2.5 , (iii) 4.0, and (iv) $4.5 \mathrm{~mm}$ from the gold electrode. As is seen in Figure $4 \mathrm{a}$, which depicts the obtained $\mathrm{Au} 4 \mathrm{f}_{5 / 2}$ and $\mathrm{Au} 4 \mathrm{f}_{7 / 2}$ doublets, a binding energy of $85.5 \mathrm{eV}$ was obtained for the $\mathrm{Au}$ $4 \mathrm{f}_{7 / 2}$ peak indicating the presence of surface-confined $\mathrm{Au}(\mathrm{I})$ thiolate species. ${ }^{43}$ The binding energy for metallic $\mathrm{Au}$ is 84.0 $\mathrm{eV}^{39}$ These results clearly show that the formation of the $\mathrm{Au}(\mathrm{I})$-thiolates is due to the oxidation of the surface-confined thiols by the $\mathrm{Au}$ (III) chloride complexes generated as a result of the oxidation of the gold electrode. Because the gradient of the $\mathrm{Au}(\mathrm{I})$-thiolate can be changed by modifying parameters such as the tilt angle, oxidation potential, hydrodynamic conditions, and chloride concentration, this approach opens up new possibilities for the straightforward generation of different protein gradients on thiolated surfaces.

The release of $\mathrm{Au}$ (III) during the oxidation was also verified by determining the gold concentration in the electrolyte after the oxidation experiment using inductively coupled plasma mass spectrometry (ICP-MS) measurements. It was found that approximately $80 \mu \mathrm{g}$ of gold was released during a $60 \mathrm{~s}$ oxidation. As discussed previously, the $\mathrm{Au}(\mathrm{III})$ chloride complexes can readily oxidize the surface-confined thiol groups provided that the local concentration of $\mathrm{Au}$ (III) species is high enough. The ICP-MS results also clearly showed that there was no significant release of $\mathrm{Au}(\mathrm{III})$ when chloride was absent in the electrolyte. As a further control, $\mathrm{Au}$ 4f photoelectron spectra were recorded for thiol-functionalized silicon surfaces that had not been exposed to any release of $\mathrm{Au}(\mathrm{III})$. In the 


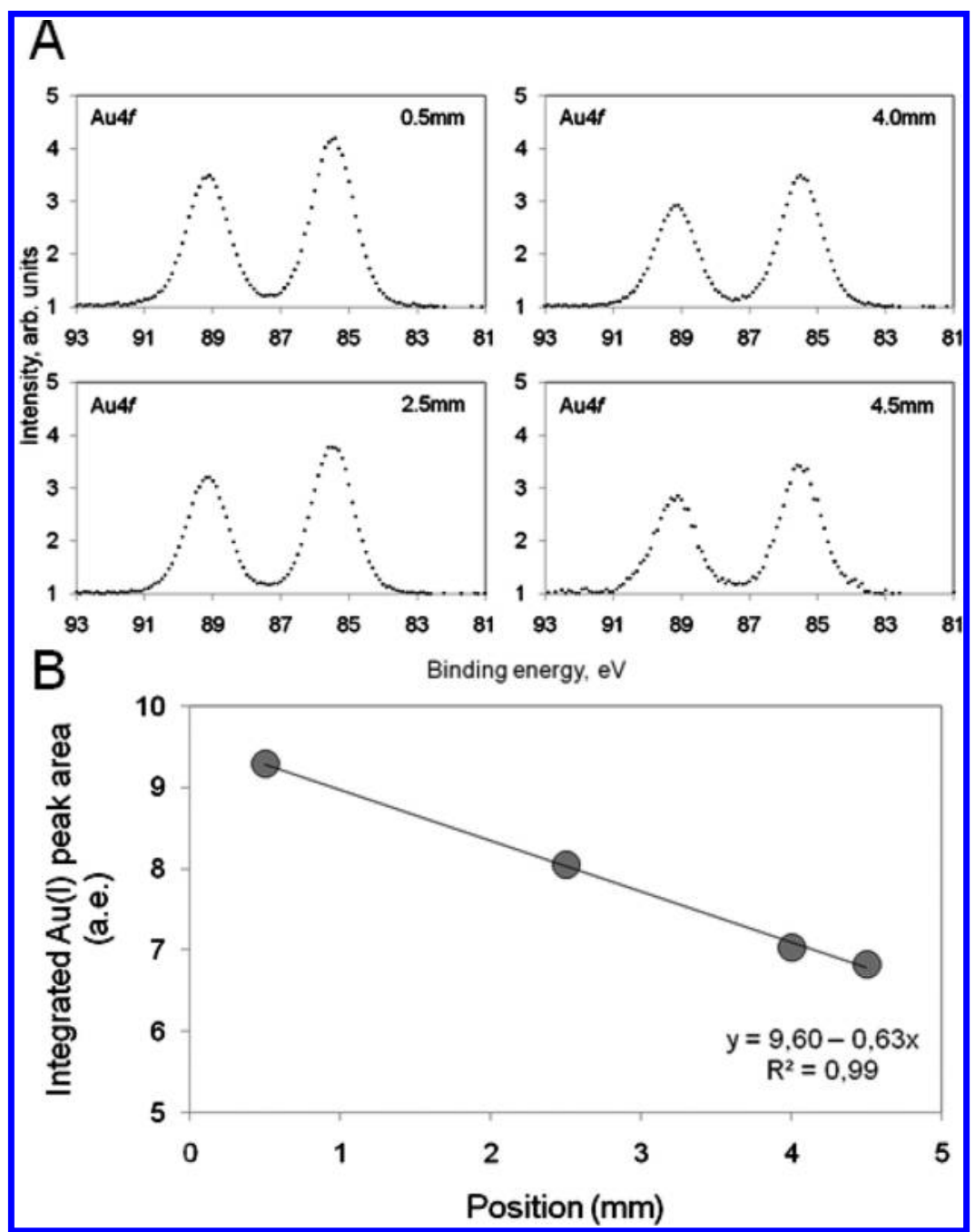

Figure 4. (A) $\mathrm{Au} 4 \mathrm{f}_{5 / 2}$ and $\mathrm{Au} 4 \mathrm{f}_{7 / 2}$ doublets recorded for the thiolated silicon surface at different positions (i.e., $0.5-4.5 \mathrm{~mm}$ ) from the gold electrode $(h \nu=1487 \mathrm{eV})$; $(\mathrm{B})$ integrated $\mathrm{Au} 4 \mathrm{f}$ peak area as a function of the position along the silicon surface. The solid line represents a linear least-squares fit based on the included equation.

latter case, there were no traces of gold on the surface of the thiolated silicon surface.

On the basis of the XPS data in Figure 4a, the integrated peak area of the $\mathrm{Au} 4 \mathrm{f}_{5 / 2}$ and $\mathrm{Au} 4 \mathrm{f}_{7 / 2}$ doublet was evaluated as a function of position along the gradient. As is seen in Figure $4 \mathrm{~b}$, the peak area decreased linearly with increasing distance from the gold surface. This finding, which is in good agreement with expectations based on the convective mass transport of the released $\mathrm{Au}(\mathrm{III})$ species away from the electrode surface, ${ }^{42}$ indicates that this approach can be used for the generation of linear $\mathrm{Au}(\mathrm{I})$-thiolate gradients that subsequently can be converted into linear protein gradients. The present approach is consequently very promising for the straightforward design of surfaces with spatially varying protein coverage.

\section{CONCLUSIONS}

A novel, straightforward electrochemical way to produce density gradients of $\mathrm{Au}(\mathrm{I})$-thiolates on the surfaces of both nonconducting spherical particles and planar surfaces has been demonstrated on the basis of the generation of $\mathrm{Au}(\mathrm{III})$-chloride complexes acting as spatially controlled oxidation agents. The generated gradients can be readily functionalized with proteins in a subsequent step to yield protein density gradients. With the present technique, it should therefore be possible to fabricate surface gradients of almost any type of thiolated molecule. The density profiles of the $\mathrm{Au}(\mathrm{I})$-thiolate or protein gradients can be controlled merely by varying the length of the oxidation potential pulse. With sufficiently short oxidation pulses, gradients on individual particles can even be obtained. For longer oxidation pulses, the protein surface concentration on different particles will differ depending on the location of the particles during the oxidation process. Moreover, the presented approach will yield not only disulfide and $\mathrm{Au}(\mathrm{I})$-protein gradients on surfaces but also gradients of nonfunctionalized surface thiols. The latter thiols can be functionalized further to provide surfaces, planar or spherical, with two protein gradients. We believe that this approach for making protein gradients with controlled density profiles will become a very versatile research tool for studies of, for example, cell migration or proliferation. Another exciting application involves the manufacturing of density gradients of thiol-supported gold nanoparticles by reducing surface-bound gold(I)-thiolates using either an electrode or sodium borohydride $\left(\mathrm{NaBH}_{4}\right)$ rather than functionalizing them with proteins. 


\section{ASSOCIATED CONTENT}

\section{S Supporting Information}

Additional experimental details and the results of investigating protein gradients on particle surfaces with fluorescence microscopy and X-ray photoelectron spectra, detecting surface-confined $\mathrm{Au}(\mathrm{I})$ species on electrochemical oxidized particles. This material is available free of charge via the Internet at http://pubs.acs.org.

\section{AUTHOR INFORMATION}

\section{Corresponding Author}

*E-mail: leif.nyholm@kemi.uu.se. Tel. +46 18 4713742. Fax +4618513548.

\section{Notes}

The authors declare no competing financial interest.

\section{ACKNOWLEDGMENTS}

We thank Dr. Jean Pettersson in the Department of Analytical and Physical Chemistry, Uppsala University for the ICP-MS measurements, and the Swedish Research Council for financial support. This letter was written through the contributions of all authors, who have given approval to the final version.

\section{REFERENCES}

(1) Liu, L.; Ratner, B. D.; Sage, E. H.; Jiang, S. Endothelial Cell Migration on Surface-Density Gradients of Fibronectin, VEGF, or Both Proteins. Langmuir 2007, 23, 11168-11173.

(2) Baum, B.; Settleman, J.; Quinlan, M. P. Transitions between Epithelial and Mesenchymal States in Development and Disease. Semin. Cell. Dev. Biol. 2008, 19, 294-308.

(3) Zhu, A. J.; Scott, M. P. Incredible Journey: How Do Developmental Signals Travel through Tissue? Genes Dev. 2004, 18, 2985-2997.

(4) Raballo, R.; Rhee, J.; Lyn-Cook, R.; Leckman, J. F.; Schwartz, M. L.; Vaccarino, F. M. Basic Fibroblast Growth Factor (Fgf2) Is Necessary for Cell Proliferation and Neurogenesis in the Developing Cerebral Cortex. I. Neurosci. 2000, 20, 5012-5023.

(5) Ashe, H. L.; Briscoe, J. The Interpretation of Morphogen Gradients. Development 2006, 133, 385-394.

(6) Larsson, A.; Liedberg, B. Poly(ethylene glycol) Gradient for Biochip Development. Langmuir 2007, 23, 11319-11325.

(7) Park, S. H.; Krull, U. A Spatially Resolved Nucleic Acid Biochip Based on a Gradient of Density of Immobilized Probe Oligonucleotide. Anal. Chim. Acta 2006, 564, 133-140.

(8) Andersson, O.; Larsson, A.; Ekblad, T.; Liedberg, B. Gradient Hydrogel Matrix for Microarray and Biosensor Applications: An Imaging SPR Study. Biomacromolecules 2009, 10, 142-148.

(9) Jayaraman, S.; Hillier, A. C. Construction and Reactivity Mapping of a Platinum Catalyst Gradient Using the Scanning Electrochemical Microscope. Langmuir 2001, 17, 7857-7864.

(10) Antoine, O.; Bultel, Y.; Ozil, P.; Durand, R. Catalyst Gradient for Cathode Active Layer of Proton Exchange Membrane Fuel Cell. Electrochim. Acta 2000, 45, 4493-4500.

(11) Keenan, T. M.; Hsu, C. H.; Folch, A. Microfluidic "Jets" for Generating Steady-State Gradients of Soluble Molecules on Open Surfaces. Appl. Phvs. Lett. 2006, 89, 114103.

(12) Jiang, X.; Xu, Q.; Dertinger, S. K. W.; Stroock, A. D.; Fu, T.; Whitesides, G. M. A General Method for Patterning Gradients of Biomolecules on Surfaces Using Microfluidic Networks. Anal. Chem. 2005, 77, 2338-2347.

(13) Noor, M. O.; Krull, U. J. Microfluidics for the Deposition of Density Gradients of Immobilized Oligonucleotide Probes; Developing Surfaces That Offer Spatial Control of the Stringency of DNA Hybridization. Anal. Chim. Acta 2011, 708, 1-10.
(14) Cosson, S.; Kobel, S. A.; Lutolf, M. P. Capturing Complex Protein Gradients on Biomimetic Hydrogels for Cell-Based Assays. Adv. Funct. Mater. 2009, 19, 3411-3419.

(15) Whittle, J. D.; Barton, D.; Alexander, M. R.; Short, R. D. A Method for the Deposition of Controllable Chemical Gradients. Chem. Commun. 2003, 1766-1767.

(16) Parry, K. L.; Shard, A. G.; Short, R. D.; White, R. G.; Whittle, J. D.; Wright, A. ARXPS Characterisation of Plasma Polymerised Surface Chemical Gradients. Surf. Interface Anal. 2006, 38, 1497-1504.

(17) Vasilev, K.; Mierczynska, A.; Hook, A. L.; Chan, J.; Voelcker, N. H.; Short, R. D. Creating Gradients of Two Proteins by Differential Passive Adsorption onto a PEG-Density Gradient. Biomaterials 2010, 31, 392-397.

(18) Halfter, W. The Behavior of Optic Axons on Substrate Gradients of Retinal Basal Lamina Proteins and Merosin. I. Neurosci. 1996, 16, 4389-4401.

(19) Peret, B. J.; Murphy, W. L. Controllable Soluble Protein Concentration Gradients in Hydrogel Networks. Adv. Funct. Mater. 2008, 18, 3410-3417.

(20) Mayer, M.; Yang, J.; Gitlin, I.; Gracias, D. H; Whitesides, G. M. Micropatterned Agarose Gels for Stamping Arrays of Proteins and Gradients of Proteins. Proteomics 2004, 4, 2366-2376.

(21) Lestelius, M.; Engquist, I.; Tengvall, P.; Chaudhury, M. K.; Liedberg, B. Order: Disorder Gradients of $n$-Alkanethiols on Gold. Colloids Surf. B 1999, 15, 57-70.

(22) Welin-Klintstrom, S.; Lestelius, M.; Liedberg, B.; Tengvall, P. Comparison between Wettability Gradients made on Gold and on $\mathrm{Si}: \mathrm{SiO}_{2}$ Substrates. Colloids Surf. B 1999, 15, 81-87.

(23) Stefonek-Puccinelli, T. J.; Masters, K. S. Co-Immobilization of Gradient-Patterned Growth Factors for Directed Cell Migration. Ann. Biomed. Eng. 2008, 36, 2121-2133.

(24) Herbert, C. B.; McLernon, T. L.; Hypolitel, C. L.; Adams, D. N.; Pikusl, L.; Huang, C.; Fields, G. B.; Letourneau, P. C.; Distefano, M. D.; Hul, W. Micropattering Gradients and Controlling Surface Densities of Photoactivatable Biomolecules on Self-Assembled Monolayers of Oligo(ethylene glycol) Alkanethiolates. Chem. Biol. 1997, 4, 731-737.

(25) Gallant, N. D.; Lavery, K. A.; Amis, E. J.; Becker, M. L. Universal Gradient Substrates for "Click" Biofunctionalization. Adv. Mater. 2007, 19, 965-969.

(26) Caelen, I.; Gao, H.; Sigrist, H. Protein Density Gradients on Surfaces. Langmuir 2002, 18, 2463-2467.

(27) Toh, C. R.; Fraterman, T. A.; Walker, D. A.; Bailey, R. C. Direct Biophotolithographic Method for Generating Substrates with Multiple Overlapping Biomolecular Patterns and Gradients. Langmuir 2009, 25, 8894-8898.

(28) Wang, S.; Foo, C. W. P.; Warrier, A.; Poo, M.; Heilshorn, S. C.; Zhang, X. Gradient Lithography of Engineered Proteins to Fabricate 2D and 3D Cell Culture Microenvironments. Biomed. Microdev. 2009, $11,1127-1134$

(29) Cai, K.; Dong, H.; Chen, C.; Yang, L.; Jandt, K. D.; Deng, L. Inkjet Printing of Laminin Gradient to Investigate Endothelial Cellular Alignment. Colloids Surf. B 2009, 72, 230-235.

(30) Morgenthaler, S.; Zink, C.; Städler, B.; Vörös, J.; Lee, S.; Spencer, N. D.; Tosatti, S. G. P. Poly-L-lysine-grafted-polyethylene Glycol-Based Surface-Chemical Gradients. Preparation, Characterization, and First Applications. Biointerphases 2006, 1, 156-165.

(31) Wang, X.; Haasch, R. T.; Bohn, P. W. Anisotropic Hydrogel Thickness Gradient Films Derivatized to Yield Three-Dimensional Composite Materials. Langmuir 2005, 21, 8452-8459.

(32) Terrill, R. H.; Balss, K. M.; Zhang, Y.; Bohn, P. W. Dynamic Monolayer Gradients: Active Spatiotemporal Control of Alkanethiol Coatings on Thin Gold Films. I. Am. Chem. Soc. 2000, 122, 988-989.

(33) Plummer, S. T.; Wang, Q.; Bohn, P. W.; Stockton, R.; Schwartz, M. A. Electrochemically Derived Gradients of the Extracellular Matrix Protein Fibronectin on Gold. Langmuir 2003, 19, 7528-7536.

(34) Lee, J. H.; Lee, H. B. Platelet Adhesion onto Wettability Gradient Surfaces in the Absence and Presence of Plasma Proteins. $I$. Biomed. Mater. Res. 1998, 41, 304-311. 
(35) Fortin, E.; Defontaine, Y.; Mailley, P.; Livache, T.; Szunerits, S. Micro-Imprinting of Oligonucleotides and Oligonucleotide Gradients on Gold Surfaces: A New Approach Based on the Combination of Scanning Electrochemical Microscopy and Surface Plasmon Resonance Imaging (SECM/ SPR-i). Electroanalvsis 2005, 17, 495-503.

(36) Ulrich, C.; Andersson, O.; Nyholm, L.; Björefors, F. Formation of Molecular Gradients on Bipolar Electrodes. Angew. Chem., Int. Ed. 2008, 47, 3034-3036.

(37) Ulrich, C.; Andersson, O.; Nyholm, L.; Björefors, F. Potential and Current Density Distributions at Electrodes Intended for Bipolar Patterning. Anal. Chem. 2009, 81, 453-459.

(38) Eriksson, K.; Johansson, L. E.; Göthelid, E.; Nyholm, L.; Oscarsson, S. Manufacturing of Anisotropic Particles by Site Specific Oxidation of Thiols. I. Mater. Chem. 2012, 22, 7681-7683.

(39) Hostetler, M. J.; Wingate, J. E.; Zhong, C.-J.; Harris, J. E.; Vachet, R. W.; Clark, M. R; Londono, J. D.; Green, S. J.; Stokes, J. J.; Wignall, G. D.; Glish, G. L.; Porter, M. D.; Evans, N. D.; Murray, R. W. Alkanethiolate Gold Cluster Molecules with Core Diameters from 1.5 to $5.2 \mathrm{~nm}$ : Core and Monolayer Properties as a Function of Core Size. Langmuir 1998, 14, 17-30.

(40) Podesta, J.; Piatti, R. C. V.; Arvia, A. J. Periodic Current Oscillations at the Gold/Acid Aqueous Interfaces Induced by $\mathrm{HCl}$ Additions. Electrochim. Acta 1979, 24, 633-638.

(41) Qi, P. H.; Hiskey, J. B. Electrochemical Behavior of Gold in Iodide Solutions. Hydrometallurgy 1993, 32, 161-179.

(42) Bard, A. J.; Faulkner, L. R. Electrochemical Methods: Fundamentals and Applications; Wiley: New York, 2001.

(43) McNeillie, A.; Brown, D. H.; Smith, W. E. X-ray Photoelectron

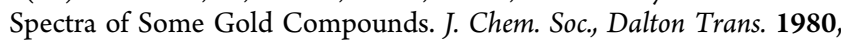
767-770.

(44) Szubera, J.; Czempika, G.; Larcipreteb, R.; Kozieja, D.; Adamowicza, B. XPS Study of the L-CVD Deposited $\mathrm{SnO}_{2}$ Thin Films Exposed to Oxygen and Hydrogen. Thin Solid Films 2001, 391, 198-203. 